This is a self-archived version of an original article. This version may differ from the original in pagination and typographic details.

Author(s): Valentini, Chiara

Title: Public relations and social influence : Understanding the roots of a contested profession

Year: 2021

Version: Published version

Copyright: (c) 2021 Mouton De Gruyter

Rights: In Copyright

Rights url: http://rightsstatements.org/page/lnC/1.0/?language=en

Please cite the original version:

Valentini, C. (2021). Public relations and social influence : Understanding the roots of a contested profession. In C. Valentini (Ed.), Public Relations (pp. 3-20). Mouton De Gruyter. Handbooks of Communication Science, 27. https://doi.org/10.1515/9783110554250-001 
Chiara Valentini

\title{
1 Public relations and social influence: Understanding the roots of a contested profession
}

\begin{abstract}
This chapter introduces the reader to the field of public relations by offering an overview of its core function and purpose. It is argued that public relations is a profession and discipline in the field of communication science that is situated at the crossroads of other social influence disciplines. Then, the chapter presents and discusses three major points of contention in the discipline: the function of public relations, the name, and its object. Next, the chapter proposes partly solving these contentions by moving away from the dichotomic view of public relations as either a managerial function or a socio-cultural practice, and instead embrace a more fluid understanding of what public relations does based on the idea of organizing. The last part of the chapter introduces the structure of the handbook and its four distinctive parts.
\end{abstract}

Keywords: public relations function; object; social influence; persuasion; organizing

\section{Introduction}

Humans, like animals, have always tried to exercise some form of social influence and change the preferences or behaviors of an individual or group. Being able to exercise social influence is an important skill for survival, as humans and animals can facilitate important group dynamics to save themselves from extinction or starvation. In humans, social influence often takes the shape of persuasion, which is an "active attempt by an individual, group, or social entity (e.g., government, political party, business) to change a person's beliefs, attitudes, or behaviors by conveying information, feelings, or reasoning" (Cacioppo et al. 2018: 129). Communication plays a key role in helping humans to achieve social influence via persuasion. In the Classical period, persuasion was considered a "rhetorical art"; old Greek rhetors had to master persuasion to exercise social influence (Heath and Bryant 2000). The body of literature on persuasion is vast and encompasses several disciplines, including communication, psychology and social psychology, neuroscience, marketing, advertising, and public relations.

The dominant understanding of public relations is linked to the concept of persuasion as a form of social influence (Miller 1989). It is generally conceptualized as $a$ specialized communication function in charge of building, supporting and maintaining positive images as well as respectful and constructive relations with publics and stake- 
holders through communication and non-communication activities. To achieve these goals, social influence may be exercised in different forms and at different levels. Given the scale and reach of public relations work, there is no doubt that public relations, like other communication disciplines, is highly dependent upon persuasion as a way to produce changes in people's opinions, behaviors, and attitudes. Sometimes, the changes occur in the target audience; other times, changes occur in the persuaders (Heath and Bryant 2000) who can persuade themselves when it is necessary to change in order to reach a common ground with the target audience.

Although there is nothing inherently wrong with the use of persuasion, the public relations profession has received more criticism than other communication professions for using it. There is a general misconception that public relations is an amoral practice that perpetuates the interests of those in power with no or limited consideration of the implications of its actions for minorities, other voices, and society at large (Lamme and Russell 2010; Coombs and Holladay 2014). Some of the derogative names assigned to public relations include spin, propaganda, demagogy, and pseudo-event (L'Etang and Pieczka 1996). Historically, public relations saw its development during wartime propaganda and post war to push commercial interests in the first half of the $20^{\text {th }}$ century. Today it is often associated with "wicked" individuals and/or organizations that recurrently make headlines in newspapers and media outlets. While it is true that still too many public relations cases involve malpractice or unethical practices, this does not mean that ethical and good public relations does not exist (Coombs and Holladay 2014). Indeed, research on public relations, activism and social engagement shows that public relations can serve more noble purposes and drive positive changes in society (Sommerfeldt 2013; De Moya and Bravo 2016; Taylor and Kent 2016; Toledano 2016). For example, it can increase the inclusiveness and engagement of different social actors and construct new forms of relations and living.

The social influence that characterizes public relations (of which persuasion is one form) should not be seen as creepy. As Heath and Bryant (2000: 174) noted, "persuasion should [...] allow people the power of self-determination" and social influence is necessary to cope with the challenges that humans have had to face since the dawn of civilization. Rather than seeing social influence in public relations as ethically wrong, what we need is a better understanding of the role that public relations plays as an institutional force that shapes our society and culture (Edwards 2018).

One of the aims of this handbook is to show that public relations is neither a manipulative profession nor a candid, unbiased one. According to Fitzpatrick and Gauthier (2003: 195), “criticism results from either a misunderstanding of or lack of appreciation for the function of public relations". Through reading this handbook, the reader will gain an understanding of the roots of this profession; what it does, how and for what purposes; and become aware of its fundamental questions and issues. It is hoped that this will help readers understand the delicate and often difficult task of balancing the interests that ethical public relations professionals need to consider 
on a daily basis, and the impact that public relations can have on how diverse social actors think and act on realities that are constructed or co-constructed around them.

In the following, an overview of some of the major points of contention regarding public relations is offered in order to introduce the reader to the field. Many of those points are further articulated, discussed, and advanced in other chapters of this handbook. In addition, the reader is introduced to the various terminologies, approaches, and views that scholars contributing to this handbook have used to present and elaborate on diverse topics.

\section{Points of contention in public relations}

There are many points of contention among public relations scholars and professionals. In the following, I review three major points that are further discussed in the contributions of this handbook.

\subsection{Function of public relations}

One of the major points of contention in public relations is the function of the profession. What public relations is and does, and whether it should be considered a profession or a practice, are hotly debated. For some, public relations lacks a clear, defined function in organizations, which can compromise the credibility of the profession (Thurlow 2009) and can make theory-building efforts more difficult to be successful or meaningful (Ferguson 2018).

Historically, public relations is situated in organizational structures with other communication and non-communication functions. Thus, many marketing scholars and professionals consider public relations to be one element of the communication mix that exists alongside advertising, sales promotions, events and experiences, publicity, and direct and personal sales (Moss et al. 1997; Kotler and Keller 2009). For advertisers, public relations is a form of unpaid, spontaneous publicity (Arens 2006; Bivins 2009). For journalists, it is a low-level reporting practice (Merkel et al. 2007; Macnamara 2014; Yoo and Samsup 2014). The problem here is not just semantic, but fundamentally an issue of recognition by other professions. The identity of public relations has been, and still is, contested because public relations professionals frequently work to support other organizational functions and often adopt practices from other professions in order to be more effective. One example of this is media relations activities; through the years, these activities have become increasingly strategic, adapting content production to the media logics that journalists tend to follow in order to increase the credibility of content and increase its reach (Ihlen and Pallas 2014). Arguably, this capacity to adapt and borrow knowledge to perform tasks should 
be seen as a positive thing, but it can create confusion regarding competence and expertise among different communication-based professions and raise professional encroachment problems. That is why some scholars have suggested departing from its original name to explain its core identity; to them, public relations should be understood as a profession about relations and relating with public(s) in the public sphere (Verčič et al. 2001; Bentele and Nothhaft 2010).

Another point of contention is related to the boundaries of public relations activities, which, most of the time, are based on their professional function. Traditionally, public relations professionals were in charge of activities that involved crafting, producing, and delivering messages through different channels and in different formats. However, an increasing number of public relations activities today, particularly those at the senior level, involve the creation and maintenance of relationships and constructive flows of communication and interactions among groups of individuals, such as consumers, customers, clients, suppliers, employees, political actors, activists, or communities.

This variation in public relations activities has led some scholars to define their function based on the effects they produce. Those who see public relations as having a symbolic function primarily believe that its main role is to construct and manage positive images and reputations, whereas those who see it as a behavioral function identify its main role as producing positive behavioral effects by, for example, building and maintaining good relationships with publics and stakeholders (Grunig J. 1993). The latter function has been perceived as superior because it is considered to involve less persuading and instead focus on reaching a common understanding that can help establish mutually beneficial relationships. Yet, it can be argued that social influence exists even in the behavioralist view in the form of, for instance, personal influence, which has been shown to be highly relevant for building and maintaining good relationships (Valentini 2010). Other scholars, particularly those who view public relations through a rhetorical lens, see this distinction as artificial and forced. For them, symbolic actions can produce noticeable behavioral effects, and behaviors often perform a symbolic function.

Although the debate on the nature of public relations is not yet settled, another debate has emerged based on the functionalistic view of public relations, according to which public relations is a function in organizations. In such debates, scholars wonder whether public relations should be defined as a specific managerial activity, thus limiting public relations to organizations, or as a social and cultural practice in its own right (Edwards 2018). The latter view detaches public relations from the mainstream understanding of an organizational function, instead positioning it as a sort of social agent with performative and agentic effects in multiple domains and contexts.

As some scholars have noted (Grunig J. 1993; Ihlen and Verhoeven 2009), the symbolic and behavioralist views are not mutually exclusive; when practiced ethically, they can coexist and serve each other's purposes. For example, constructing a positive image of an organization, individual, or entity (symbolic function) may help public 
relations' efforts to reach out and build relationships with publics and stakeholders (behavioral function). Conversely, good relationships can support the public image of an organization.

Thus, public relations is more than just another organizational function, if we narrowly define organizations as "a stable association of persons engaged in concerned activities directed to the attainment of specific objectives” (Valentini 2018: 2). For some time, organizational theorists have proposed abandoning this concept of an organization - a stable structure - in favor of the concept of organizing, a more fluid idea that includes developing collective structures and practices in which communication can play an important constitutive role (Weick 1979; 1995; Robichaud and Cooren 2013). From a post-structuralist approach, I argue that seeing public relations as an organizing function instead of an organizational function represents what public relations has done and can do for publics, stakeholders, and societies, as a powerful force that impacts opinions, behaviors, societal norms, cultures, and ways of thinking. Understanding public relations as an organizing function emphasizes agency rather than the loci of functions, and it can better illustrate the back-and-forth movement and translation between the actions of public relations and their interpretation by professionals as well as publics (Weick 1979). The notion of organizing could bring some closure to the debate on whether public relations is an organizational function, as it allows for a more fluid definition of what public relations is and does for/to organizations, publics, societies, and cultures.

\subsection{Name of public relations}

The questions and debates outlined above raise the issue of the name of public relations, which has become imperative to address. Several educational programs in universities across the world have changed their names to "strategic communication", "corporate communication" or "communication management”. Should public relations evolve with the latest development of tasks, activities, and professional needs? Should it change its name to reflect its newer identity?

Perhaps because of the bad legacy of the term "public relations", or perhaps because the profession has developed new venues of interest and become more integrated, professionals across the world use a variety of different names and titles to describe public relations. The debate regarding this is more animated among academics than professionals, as the latter do not seem to see a problem in switching names. According to the European Communication Monitor, most professionals prefer to use the term "corporate communication" in their professional titles, followed by "strategic communication" and "public relations" (Zerfass et al. 2011).

Scholars who position themselves within the strategic communication field do not want to be confused with public relations scholars. Although they recognize the common roots of these fields, in their view, strategic communication is a different 
field. Specifically, strategic communication is defined as "the practice of deliberate and purposive communication that a communication agent enacts in the public sphere on behalf of a communicative entity to reach set goals" (Holtzhausen and Zerfass 2013: 284). It can encompass activities related to management, marketing, public relations, technical communication, political communication, and information/social marketing campaigns (Hallahan et al. 2007). Unlike public relations, it is perceived to offer an integrative perspective on all goal-oriented communications of an organization (Frandsen and Johansen 2018). Today, it is the preferred term to describe public relations activities for non-corporate entities; for instance, it is commonly used to define communication functions in public sector organizations and government entities (Nielsen and Salomonsen 2012; Valentini 2013; Fredriksson and Pallas 2016).

In the business world, "corporate communication" has emerged as the preferred term, although there are some country-specific preferences for professional names due to different historical reasons and influence from professional bodies. Similar to strategic communication, it is claimed that corporate communication is much more than public relations. It is used as an umbrella term to describe a variety of communication forms and formats, including public relations, public affairs, and employee, customer, and stockholder communications (Cornelissen 2017). Corporate communication is also like strategic communication in that it is goal-oriented, focusing on managing and coordinating different forms of communication to provide a consistent image of an organization to all its stakeholders (van Riel 1995).

This terminological issue may seem ridiculous at times, but it is important to epistemologically reflect on the meanings of names and their impact on how the profession of public relations is understood by practitioners, the general public and by other communication and non-communication professions. The different nuances of the terms used to describe communication professionals' identity can lead the research community to investigate different issues, ask different research questions, and thus theorize differently on this discipline. Yet, I argue that this problem could be partially solved if we understand that public relations, strategic communication, corporate communication, and communication management are organizing functions, rather than organizational functions, and focus on understanding, exploring, and analyzing their different practices and their impact on organizations, publics, stakeholders, and societies. From this perspective, contention regarding terminology becomes less important because the unifying element across these very similar communication professions is their capability to organize something for or on behalf of someone.

While this handbook primarily focuses on public relations, an attentive reader will notice that the reflections and discussions parallel questions and issues raised in the strategic and corporate communication disciplines. As this matter is quite important for the evolution of public relations, some contributors have purposely decided to use either of these terms instead of "public relations" to emphasize the view and perspective adopted in their discussion. 


\subsection{The object of public relations}

The third point of contention concerns the object of public relations. Does public relations deal with publics, stakeholders, or both? Early conceptual developments in public relations are grounded on the work of Dewey (1927), in which the public is predominantly regarded from a situational perspective as a group of individuals with whom public relations interacts (Rawlins and Bowen 2005). Yet, other perspectives, such as mass media, agenda building, and homo narrans, have also been identified in public relations research (Vasquez and Taylor 2001). Most public relations literature considers publics to be groups of individuals who face a similar problem, recognize it, and organize themselves to address it, regardless of whether they have a direct interest in any organization involved with the issue (Dewey 1927).

During the last forty years, the management school of thinking has taken several stances on public relations vocabulary. During the 1980s, public relations started to become more interested in relationship management, which may have led to more interest in drawing upon management terminology. The term "stakeholder" emerged as an alternative way to describe groups of individuals who directly impacted or are impacting the operations of an organization and whose interests are closely tied to the organization's business (Freeman 1984). However, J. Grunig and Repper (1992) warn that "stakeholder" and "public" are not interchangeable: "Stakeholders are people who are linked to an organization because they and the organization have consequences on each other" (127), whereas publics "arise on their own and choose the organization for attention" (128). Essentially, publics are groups of individuals that form in response to a particular problem, not necessarily because they possess a stake or interest in the organization, and they are defined through their communications. In contrast, stakeholders are defined by the management of an organization, and they may not be consciously aware that they are part of a stakeholder group.

Yet, a clear distinction between the two terms is not always so evident. In addition to the terminological dispute (Mackey 2006), the distinction between stakeholders and publics has dissolved for the most part, and so has the distinction between primary and secondary stakeholders (Ihlen 2008). Kruckeberg and Vujnovic (2010) go even further and claim that the concept of publics is dead in contemporary society. Without taking such a radical view, and considering that prioritization and management are key interests for any organization, I argue that societal expectations regarding organizations' responsibilities have extended so far that it is almost impossible not to look at a broad spectrum of specialized and non-specialized interests. The relations and interactions among organizations, publics, and stakeholders are so complex and nonlinear that it no longer makes sense to distinguish between publics and stakeholders. In part, this broadening is the result of the increasing complexity of today's environment (Hurth 2017). It is evident that public relations must be able to navigate and adapt to this environment in order to build, support and maintain relations and interactions with a variety of different stakeholders and publics, whose interests 
often collide and may be irreconcilable. To overcome this challenge, public relations is asked to perform a number of very different organizing activities at the societal, cultural, political, economic, and interpersonal levels.

In this handbook, both terms (i.e. stakeholders and publics) have been used, sometimes interchangeably and sometimes with specific reference to the original differentiation. In fact, it is evident from the contributions that there is contention regarding the concepts among authors. This partially reflects the authors' preferences and partially their academic roots and philosophical stances. While the terms may vary and carry different meanings, there is one thing that remains stable: the object of public relations. Public relations aims at exercising some form of social influence on other social actors and agents via communication to achieve symbolic and/or behavioral effects. Terminological discussions are important, but we must not forget that all public relations deals with many different social actors, exercises some influence and performs an organizing role while interacting, constructing, and deconstructing the environment in which activities take place.

\section{The structure of this handbook}

The purpose of this handbook is to present and offer a deeper understanding of the public relations profession and the body of knowledge that public relations scholars have developed over the years. The reader is offered a compilation of key classical public relations theories and recent theorizing in public relations as well as key models and concepts. The section on public relations thoeries contains those theories that are considered classical public relations contributions, whereas the section on recent theorizing in public relations deals with recent theorizing efforts undertaken by scholars to expand the body of knowledge. The theories, concepts and models presented in this volume are explained, and critically discussed to offer an understanding of the theoretical and practical contributions of public relations as an applied communication science. It is important to note that the handbook does not include all theoretical perspectives in the field. For instance, political and not-for-profit-related topics in the public relations discipline have been purposively left out since other volumes on these specific topics exist within the De Gruyter Mouton collection. Furthermore, deliberate choices had to be made about what to include and exclude in the part on emergent theoretical developments, as it was not possible to cover all new thinking in the field from the last ten years within one volume.

The chapters are organized into four thematic parts: Part I - History, identity and practice; Part II - Core functions of public relations; Part III -Theories of public relations; and Part IV - Recent theorizing in public relations. This handbook is structured to take the reader on a journey to explore, first the profession (part I and II), and later the discipline of public relations (part III and IV). Part I delves into what the profession 
is and how it has developed and the major debates on how the profession should move and how it is affecting society. Part II focus on professional activities and functions that are typically undertaken by public relations. The last two parts are dedicated to the theoretical contributions of public relations as distinct communication discipline.

\subsection{Part I - Public Relations: History, Identity, and Practice}

Part I presents and discusses questions related to the origins, evolution, and identity of public relations as a profession and field of study from a global perspective. In Chapter 2, Rodriguez-Salcedo and Watson take the reader on an historical "excursion" regarding the origins and roots of public relations around the world. Although limited by the chapter length, the authors show that the roots of this profession are much deeper and more culturally varied that we may realize, and so are the meanings that people around the world ascribe to this profession.

Following this, Chapter 3 reviews and discusses the specific contributions and roles women had and have in the development and professionalization of public relations. As Tooth and Aldoory emphasize, women are the largest group of professionals in many societies, and hence they play a great role in determining what public relations can accomplish within organizational settings and the larger societies in which organizational public relations operates.

Speaking of professional influence, in Chapter 4, Fawkes questions the premise of considering public relations as a distinct profession. She explores the tensions between different forces that shape professional identity and the resulting identity conflicts, particularly those regarding ethical responsibility. She concludes with suggestions for shaping this profession's identity through the development of global capabilities.

Continuing the discussion of the identity of public relations, in Chapter 5, van Ruler addresses the important question of what value public relations may offer to organizations and society by discussing how public relations can enhance a professional reflective culture in which societal expectations are part of the organizational public relations practice.

Taking this as a point of departure, in Chapter 6, Bartlett and Hurst address the fundamental nature of legitimacy in public relations. After explaining and offering a reading of key legitimacy literature, they discuss the idea that vying for legitimacy and reputation has become a central part of the practice of public relations related to explaining organizations and maintaining support.

The last chapter in Part I, Chapter 7, is a piercing discussion of one of the main criticisms of public relations through the years, which concerns its presumed power to influence others. Weaver introduces the reader to the paradoxes of power and control that constitute its identity as well the main critique of this profession and suggests some reflections on how to address power in public relations. 


\subsection{Part II - Core Functions of Public Relations}

Part II addresses some of the core functions of the public relations profession today. While there are differences across organizational settings and activities, the contributors focus on the activities that are expected of one who is competent in public relations.

This part starts with a chapter on one classical public relations activity, media relations. In Chapter 8, Tsetsura provides a critical overview of media relations approaches, from agenda-setting and framing to journalist-public relations relationships. This is done to understand the complexity of relationship-building with traditional media and non-traditional stakeholders who have their own mediated channels.

Next, in Chapter 9, Etter, Winkler, and Pleil elaborate on how social media have developed over the last 15 years from a niche area to disruptive and dominating phenomena in the context of public relations. The authors offer four approaches to understand the development of social media research and practice and then discuss the contributions to public relations.

In line with the symbolic view of public relations, in Chapter 10, Murtarelli, Romenti, and Carroll introduce the reader to two parallel sets of understandings pertaining to image and reputation management. The chapter highlights the role of public relations in managing image and reputation, illustrates its contributions to construct and maintain positive images and a good reputation on behalf of an organization, individual or entity, and identifies opportunities and risks that professionals could face in the current competitive environment.

Speaking about risks to image and reputation, in Chapter 11 Diers-Lawson and Pang examine the field of strategic issue and crisis management as an important public relations activity involving management of risk to minimize or mitigate dangers in order to preserve an organization's image. The authors conclude by offering some insights into the strategic management of crises, issues, and risks.

The next two chapters take a social turn and discuss the function of public relations in the context of stakeholder and societal engagement and social advocacy. In Chapter 12, Holladay and Tachkova describe how stakeholder theory provides a foundation for understanding organization-stakeholder engagement processes. In doing so, they help position public relations as an engagement activity that creates value through corporate social responsibility and sustainable development. In Chapter 13, Williams and Sommerfeldt advance our notion of public relations as a practice that involves social influence by focusing on social advocacy as a specific public relations activity that can strengthen connections between an organization, its constituent publics, and society. Through the lens of communitas, which is an orientation to serve the community and the public sphere, these authors discuss how public relations can serve the public good and be a positive force in society.

The last chapter addresses the important question of how to measure and evaluate the impact of public relations activities. In Chapter 14, Macnamara reviews the 
current state of practice and the latest evaluation frameworks and models that are used internationally. In addition, he outlines the key concepts and principles for the three stages of formative, process and summative evaluation. Macnamara concludes by offering suggestions for best practices and new directions for the future of measurement and evaluation.

\subsection{Part III - Theories of Public Relations}

Part III presents main theories and theoretical perspectives related to public relations. The theories and models discussed here are considered part of classical public relations theory, although some more recent versions of well-known theories are included with a theoretical review that can lead to reflections for future theorizing and a critical evaluation of the applicability of the theory to practice. An attentive reader may find similarities between the concepts and ideas presented in this part and those of other disciplines. Much public relations theory is an interdisciplinary melting pot as scholars have used concepts and ideas from other disciplines to bring new lines of thinking to the field of public relations. Paraphrasing J. Grunig (personal communication 22 February 2017), usually, concepts from other disciplines must be adapted to fit to public relations problems. Thus, even though the theories presented in this part were constructed based on concepts from many other disciplines, they can be considered classical public relations theories.

In Chapter 15, J. Grunig and Kim introduce the reader to the evolution of thought surrounding the Four models of public relations and their relevance and applicability to today's professional world. The four models, which describe four different ways of communicating and conducting public relations, are considered early classical public relations theoretical contributions.

In Chapter 16, Hung-Baesecke, Chen, and Ni present another classical public relations theory, Excellence theory. The scholars offer an overview of its origins, developments and contributions to the body of knowledge in public relations. They conclude by advancing some ideas for future research topics derived from this theory.

Chapter 17 introduces one of the least studied models of public relations, the Personal influence model. Sriramesh and Fisher warn that personal influence, as a form of social influence exercised by public relations professionals on other individuals, is practiced widely across cultures and not just in collective societies. The authors conclude by offering their thoughts on the importance of personal influence in the public relations field as well as avenues for further research.

Chapter 18 draws the reader's attention to rhetoric and its important function in persuasive communications (and thus in public relations). Through a compelling review and discussion, Heath, Waymer and Ihlen introduce the Rhetorical theory of public relations and discuss its normative and instrumental functions in public relations. According to the scholars, the rhetorical theory offers a theoretical ground to 
help public relations construct discourses for the strategic purpose of managing relatedness. While this theory focuses on textual enactment, the next chapter deals with stance enactment in communication processes.

Chapter 19 presents another classical public relations theory, Contingency theory. Pang, Yan, and Cameron argue that this theory fulfils the requirements for being considered a grand theory of public relations since it explains the job of public relations, which is essentially to mitigate conflict by adapting communications. Contingency theory clarifies that this adaptation process is possible by enacting a variety of stances depending on the circumstances.

The idea of adaptability is also central in Chapter 20, which focuses on global public relations theories and theoretical approaches. Chaidaroon and Hou review and discuss four major approaches to studying and theorizing about global public relations. All these approaches share a general assumption that public relations practices involve meaning-making, discourse production and relationship-building, and that such activities must be adapted to different situational and contextual elements, of which culture plays a key role. The scholars remind readers that global public relations is both a product of globalization and an agent that produces economic, political and socio-cultural flows of globalization.

In Chapter 21, Ledingham, one of the major contributors to Relationship management theory, presents the roots of his thinking on relationship management, from the initial premises to its increasing relevance in contemporary practice and definition of the public relations profession.

The concept of relations is central in Chapter 22, where Vujnovic, Kruckeberg, and Starck explain the roots of Community-building theory and its subsequent development into an Organic theory of public relations. Both theories postulate a normative, societal role of public relations. The scholars argue that public relations practitioners have an important responsibility to maintain and change societal relations. They are community-builders who, through communication, should strive to maintain and restore a sense of community.

This sense of community can be enhanced by dialogic communications. As Lane notes in Chapter 23, much research on public relations that deals with community, relationships, and similar topics focuses on dialogue. This could be associated with the desire of professionals and scholars to better understand the type of communication that can help to build and maintain positive relationships with publics and stakeholders. Lane offers an incisive review of the evolution of another classical theory, the Dialogic theory of public relations, linking it to the wider philosophical discussion of dialogue as a concept, and offering suggestions for future theorizing.

The last chapter in Part III deals with the identification and classification of publics in public relations. In Chapter 24, Kim, Tam, and Chon present another established public relations theory, the Situational theory of publics, as well as its origins and its evolution into the Situational theory of problem-solving. As these scholars noted, for public relations, it is paramount to understand how publics behave when specific 
issues arise and what type of communication may be needed. This understanding helps practitioners to identify the best strategies for responding to demands. The main assumptions of these theories is that we must see communication as a process that individuals undertake to manage problematic life situations.

\subsection{Part IV - Recent Theorizing in Public Relations}

The last section of this handbook addresses emerging theories for public relations that are not part of the classical tradition but were developed in other disciplines and have resonated with some public relations scholars, as well as efforts to further theorize about public relations. These scholars have tried to translate and adapt classical knowledge from disciplines such as sociology, management, organizational and cultural studies, and philosophy, and reposition it to tackle complex problems.

In Chapter 25, Hazleton and Tydings review a classical sociological theory (i.e. social capital theory) and link it with the behavioralist view of public relations, which emphasizes the impact of building social capital in relationships. These authors propose three theoretical constructs to advance social capital theory and facilitate its use as a practical theory for the community of public relations professionals.

Chapter 26 takes a different route, deconstructing the identity of public relations based on the Scandinavian idea of institutionalism. Through a provoking discussion, Fredriksson, Ivarsson, and Pallas challenge the idea of a public relations function or role. For them, public relations is a management idea, and as such, its essential purpose is to achieve better management. This understanding, the scholars argue, would allow for multiple interpretations of what public relations is and does in different organizations over time without imposing one single view. It would also calm the terminological debates between "public relations", "strategic communication", "corporate communication" and others, since such distinctions are irrelevant if public relations has the flexibility to be translated and adapted across contexts and situations.

Chapter 27 also focuses on current professional challenges caused by the instability, volatility, and uncertainty of the environments in which public relations operates. The reader is introduced to Actor-Network Theory, which Somerville argues can offer important insights into the practice of public relations. From an Actor-Network Theory perspective, all human, technological, textual, or natural entities are important "social" actors, and they can all acquire power by placing themselves at the center of a network. Hence, understanding diverse social actors' behaviors and the dynamics of social influence can help a public relations professional to influence other actors' positions in a way that benefits the organization or entity on whose behalf the professional is acting.

Moving towards management, in Chapter 28, Olkkonen and Luoma-aho introduce the idea of managing stakeholder expectations. According to them, expectations 
provide organizations with information and cues about stakeholders' and publics' values, interests, experiences and knowledge, which are important for strategic public relations planning. After introducing the field of expectations and its relevance, the scholars advance propositions for a Relationship expectation theory in public relations.

Chapter 29 provides an understanding of what culture is and how it impacts public relations activities. Curtin offers an overview of the nexus of public relations and cultural theories and presents acute reflections on how culture is translated across different approaches and epistemological lines of thinking. She concludes by elaborating on the contribution of culture to our understanding of different practices of public relations.

The last chapter of Part IV deals with ethics and ethical theories. In Chapter 30, Bowen and Bhalla discuss ethical issues and challenges facing public relations from an organizational perspective in an increasingly global environment. These authors introduce the overarching concepts of normative (ideal) and positive (descriptive) ethics, followed by the two most prominent forms of normative ethics: utilitarianism and deontology. The chapter concludes by offering suggestions for how to include more ethical thinking in contemporary public relations decision-making.

The last two chapters of this handbook offer the reader some critical thoughts about public relations and some conclusions. In Chapter 31, Bourne and Edwards call for more reflexivity and scrutiny of how public relations operates, emphasizing the effect of public relations on society. The scholars also invite giving more attention to diverse voices and to diversity in public relations. Chapter 32, written by Valentini, offers a meta-theoretical analysis of the so-called classical public relations theories presented in this handbook, and shows some continuities and discontinuities in the academic discourse about what public relations is and does and what knowledge we have.

\section{Concluding thoughts}

This handbook is part of a series of existing and forthcoming handbooks by de Gruyter Mouton that provides in-depth and broad perspectives on different communication topics. The handbook is one of the first of its kind as it tries to reach scholars, students, practitioners, and readers who are not familiar with public relations activities and theories. Yet, its contents go beyond an introduction to public relations; the scholars represented here have purposively worked to build coherent and critical texts that speak to multiple voices and views. Public relations is a multi-faceted profession, and thus it must be understood from a wide perspective based on solid theoretical foundations in other communication and non-communication disciplines.

The handbook brings together scholars from different parts of the world and from very different theoretical and disciplinary traditions. It includes old and new schools of 
thinking, as well as established and emergent scholars. The diversity of these perspectives is considered a strength of this handbook, as it encapsulates several variations and understandings of public relations. Scholars and practitioners alike can utilize this handbook as an account of what public relations is, does, and contributes to. In reviewing the public relations discipline, this collective work fills some important gaps in the knowledge and stimulates further thought and action. I hope you enjoy reading this handbook and feel inspired to push boundaries while exploring existing or new lines of thinking. The profession and discipline of public relations will benefit from future theorizing in and for public relations, and I hope you will consider contributing to the advancement of our professional and disciplinary understanding of this topic.

\section{References}

Arens, William F. 2006. Contemporary advertising. New York: McGraw-Hill

Bentele, Günter \& Howard Nothhaft. 2010. Strategic communication and the public sphere from an European perspective. International Journal of Strategic Communication 4(2). 93-116

Bivins, Thomas. 2009. Mixed media: moral distinctions in advertising, public relations, and journalism. New York: Routledge,

Cacioppo, John T., Stephanie Cacioppo \& Richard E. Petty. 2018. The neuroscience of persuasion: A review with an emphasis on issues and opportunities. Journal of Social Neuroscience 13(2). 129-172.

Coombs, Timothy W. \& Sherry J. Holladay. 2014. It's Not Just PR: Public Relations in Society, 2nd edn. Chichester, UK: Wiley Blackwell.

Cornelissen, Joep. 2017. Corporate communication: A guide to theory and practice, $5^{\text {th }}$ edn. London: sage

De Moya, Maria \& Vanessa Bravo. 2016. The role of public relations in ethnic advocacy and activism: A proposed research agenda. Public Relations Inquiry 5(3). 233-251.

Dewey, John. 1927. The Public and Its Problems. Chicago: Swallow Press.

Edwards, Lee. 2018. Understanding public relations. Theory, culture and society. London: Sage.

Ferguson, Mary Ann. 2018. Building theory in public relations: Interorganizational relationships as a public relations paradigm. Journal of Public Relations Research 30(4). 164-178.

Fitzpatrick, Kathy \& Candace Gauthier. 2003. Toward a professional responsibility theory of public relations ethics. Journal of Mass Media Ethics 16(2/3). 193-212.

Frandsen, Finn \& Winni Johansen. 2018. Strategic communication. In Craig R. Scott \& Laurie Lewis (eds), International Encyclopedia of Organizational Communication. Malden, MA: Wiley Blackwell.

Fredriksson, Magnus \& Josef Pallas. 2016. Diverging principles for strategic communication in government agencies. International Journal of Strategic Communication 10(3). 153-164.

Freeman, Edward R. 1984. Strategic Management: A Stakeholder Approach. Cambridge: Cambridge University Press.

Grunig, James E. 1993. Image and Substance: From symbolic to behavioral relationships. Public Relations Review 19(2). 121-139.

Grunig, James E. \& Fred C. Repper. 1992. Strategic management, publics, and issues. In James E. Grunig (ed.), Excellence in Public Relations and Communication Management, 117-157. Hillsdale, NJ: Lawrence Erlbaum Associates. 
Hallahan, Kirk, Derina R. Holtzhausen, Betteke van Ruler, Dejan Verčič \& Krishnamurthy Sriramesh. 2007. Defining strategic communication. International Journal of Strategic Communication 1(1). 3-35.

Heath, Robert L. \& Jennings Bryant. 2000. Human Communication Theory and Research, $2^{\text {nd }}$ edn. Mahwah, NJ: Lawrence Erlbaum Associates.

Holtzhausen, Derina R. \& Ansgar Zerfass. 2013. Strategic communication: Pillars and perspectives on an alternative paradigm. In Krishnamurthy Sriramesh, Ansgar Zerfass \& Jeon-Nam Kim (eds.), Current trends and emergent topics in public relations and communication management, 283-302. New York: Routledge.

Hurth, Victoria. 2017. Organizations as open systems that need purpose and integrated thinking. Board Leadership: Innovative Approaches to Governance 150.1-8.

Ihlen, Øyvind. 2008. Mapping the environment for corporate social responsibility: stakeholders, publics and the public sphere. Corporate Communications: an International Journal 13(2). 135-146.

Ihlen, Øyvind \& Josef Pallas. 2014. Mediatization of corporations. In Knut Lundby (ed.), Mediatization of Communication, Handbooks of communication science 21, 423-442. Berlin: De Gruyter Mouton.

Ihlen, Øyvind \& Piet Verhoeven. 2009. Conclusions on the domain, context, concepts, issues, and empirical venues of public relations. In Øyvind Ihlen, Magnus Fredriksson \& Betteke van Ruler (eds.), Public relations and social theory: Key figures and concepts, 322-340. New York: Routledge.

Kotler, Philip \& Kevin L. Keller. 2009. Marketing Management, $13^{\text {th }}$ edn. Upper Saddle River, NJ: Pearson Prentice Hall.

Kruckeberg, Dean \& Marina Vujnovic. 2010. The death of the concept of publics (plural) in 21st century public relations. International Journal of Strategic Communication 4(2). 117-125.

Lamme, Margot 0. \& Karen M. Russell. 2010. Removing the spin. Toward a new theory of public relations history. Journalism and Communication Monographs 11(4). 281-362.

L'Etang, Jacquie \& Magda Pieczka. 1996. Critical perspectives in public relations. London: Cengage Learning Emea.

Mackey, Steve. 2006. Misuse of the term 'stakeholder' in public relations. PRism 4(1). http://praxis. massey.ac.nz/prism_on-line_journ.html (accessed 28 January 2020).

Macnamara, Jim. 2014. Journalism-PR relations revisited: The good news, the bad news, and insights into tomorrow's news. Public Relations Review 40(5). 739-750.

Merkel, Bernd, Stephan Russ-Mohl \& Giananni Zavaritt. 2007. A Complicated, Antagonistic, Symbiotic Affair: Journalism, Public Relations and Their Struggle for Public Attention. Lugano, Switzerland: Università della Svizzera Italiana.

Miller, Gerald R. 1989. Persuasion and public relations: Two p's in a pod. In Carl H. Botan \& Vincent Hazleton (eds.), Public Relations theory, 45-66. Hillsdale NJ: Lawrence Erlbaum Associates.

Moss, Danny, Gary Warnaby \& Louise Thame. 1997. Public relations or simply product publicity? In Danny Moss, Toby MacManus \& Dejan Verčič (eds.), Public relations research: an international perspective, 135-158. London: International Thompson Business Press.

Nielsen, Jeppe Agger \& Heidi Houlberg Salomonsen. 2012. Why all this communication? Explaining strategic communication in Danish local governments from an institutional perspective. Scandinavian Journal of Public Administration 16(1). 69-89.

Rawlins, Brad L. \& Shannon A. Bowen. 2005. Publics. In Robert L. Heath (ed.), Encyclopedia of Public Relations. London: Sage.

Robichaud, Daniel \& François Cooren. 2013. Organization and Organizing: Materiality, Agency, and Discourse. New York: Routledge. 
Sommerfeldt, Erich J. 2013. The civility of social capital: Public relations in the public sphere, civil society, and democracy. Public Relations Review 39. 280-289.

Taylor, Maureen \& Michael Kent. 2016. Nation building in the former Yugoslavia. A 20-year retrospective to understand how public relations rebuilds relationships in divided societies. In Ian Somerville, Owen Hargie, Maureen Taylor \& Margalit Toledano (eds.), International Public Relations. Perspectives from deeply divided societies, 9-26. London: Routledge.

Thurlow, Amy. 2009. “I just say I'm in advertising”: A public relations identity crisis? Canadian Journal of Communication 34. 245-263.

Toledano, Margalit. 2016. Advocating for reconciliation: Public relations, activism, advocacy and dialogue. Public Relations Inquiry 5(3). 277-294.

Valentini, Chiara. 2010. Personalised networks of influence in public relations: Strategic resources for achieving successful professional outcomes. Journal of Communication Management 14(2). 153-166.

Valentini, Chiara. 2013. Public relations in the public sector. The role of strategic communication in the Italian public administration. Sinergie: Italian Journal of Management 92. 93-113.

Valentini, Chiara. 2018. Communicatively constituted stakeholders: Advancing a communication perspective in stakeholder relations. In Adam Lindgreen, Francois Maon, Joelle Vanhamme, Beatriz Palacios Florencio, Christine Strong \& Carolyn Vallaster (eds.), Engaging with Stakeholders: A Relational Perspective on Responsible Business, 65-79. New York: Routledge

Vasquez, Gabriel M. \& Maureen Taylor. 2001. Research perspectives on "the Public". In Robert L. Heath (ed.), Handbook of Public Relations, 139-154. London: Sage.

Verčič, Dejan, Betteke van Ruler, Gerhard Bütschi \& Bertil Flodin. 2001. On the definition of public relations: a European view. Public Relations Review 27(4). 373-387.

van Riel, Cees B. M. 1995. Principles of Corporate Communication. Harlow, UK: Prentice Hall. Weick, Karl E. 1979. The Social Psychology of Organizing, 2nd edn. New York: McGraw-Hill.

Weick, Karl E. 1995. Sensemaking in Organizations. London: Sage

Zerfass, Ansgar, Piet Verhoeven, Ralph Tench, Angeles Moreno \& Dejan Verčič. 2011. European Communication Monitor 2011: Empirical insights into strategic communication in Europe. Brussels: EACD, EUPRERA.

Yoo, Jae-Woong \& Samsup Jo. 2014. How do journalists express their perceptions of public relations on Twitter? Social Behavior \& Personality: An International Journal 42 (7). 1175-1182. 
